\title{
Prevalence of underlying lung disease in smokers with epidermal growth factor receptor-mutant lung cancer
}

\author{
AKIMASA SEKINE ${ }^{1}$, KATSUMI TAMURA $^{2}$, HIROAKI SATOH $^{3}$, TOMOAKI TANAKA $^{4}$, YOSHIYA TSUNODA $^{1}$, \\ TORU TANAKA ${ }^{1}$, HIROYUKI TAKOI ${ }^{1}$, SHIH-YUAN LIN ${ }^{1}$, YOHEI YATAGAI ${ }^{1}$, TOSHINORI HASHIZUME ${ }^{5}$, \\ KENJI HAYASIHARA ${ }^{1}$ and TAKEFUMI SAITO ${ }^{1}$
}

\author{
Departments of ${ }^{1}$ Respiratory Medicine, and ${ }^{2}$ Radiology, National Hospital Organization, Ibarakihigashi National Hospital, \\ Naka-gun, Ibaraki 319-1113; ${ }^{3}$ Department of Internal Medicine, Mito Medical Center, University of Tsukuba, \\ Mito, Ibaraki 310-0015; ${ }^{4}$ Department of Respiratory Medicine, Saitama Medical School, Iruma-gun, \\ Saitama 350-0400; ${ }^{5}$ Department of General Thoracic Surgery, National Hospital Organization, \\ Ibarakihigashi National Hospital, Naka-gun, Ibaraki 319-1113, Japan
}

Received November 9, 2012; Accepted January 24, 2013

DOI: $10.3892 /$ or.2013.2320

\begin{abstract}
The prevalence of underlying lung diseases, such as emphysema and interstitial lung disease in smokers with epidermal growth factor receptor (EGFR)-mutant lung cancer remains unclear. This study aimed to clarify the correlation between the EGFR mutation status and the prevalence of underlying lung disease in smokers with lung cancer. A total of 88 consecutive smokers with non-small cell or nonsquamous cell lung cancer who underwent surgical resection at our hospital from January 2007 through December 2010 were included in this study. The patients were divided into two groups on the basis of the EGFR mutation status: the mutationpositive group $(n=19)$ and the wild-type group $(n=69)$. The results of radiographic assessment via computed tomography (CT) and pulmonary function analysis were compared between the two groups. In the radiological evaluation, CT images at three levels were evaluated by two reviewers. Radiographic assessment revealed that the mutation-positive group tended to have milder emphysematous changes and a lower prevalence of interstitial changes compared with the wild-type group $(\mathrm{P}=0.13$, 0.06). When the analysis was limited to the ipsilateral lung at the nearest $\mathrm{CT}$ level to the tumor, emphysematous changes were found to be less common in the mutation-positive group $(\mathrm{P}=0.02)$. The prevalence of the emphysematous and/or interstitial changes in the ipsilateral lung at the nearest CT level to the tumor was lower in the mutation-positive group compared to the wild-type group $(\mathrm{P}=0.005)$. In the pulmonary function test, the results were comparable between the two groups. In
\end{abstract}

Correspondence to: Dr Akimasa Sekine, Department of Respiratory Medicine, National Hospital Organization, Ibarakihigashi National Hospital, Terunuma 825, Tokai-mura, Naka-gun, Ibaraki 319-1113, Japan

E-mail: Akimasa.Sekine@gmail.com

Key words: epidermal growth factor receptor mutation, lung cancer, emphysema, interstitial lung disease, smoker conclusion, according to our results, EGFR-mutant lung cancer was commonly observed in the areas where emphysematous and interstitial changes were absent. EGFR-mutant lung cancer may develop in radiographically normal areas of the lungs, even in smokers. It would be of importance to evaluate the EGFR mutation status in patients with no emphysematous or interstitial changes in the ipsilateral lung near the tumor, regardless of their smoking history. These results should be confirmed in a future prospective study.

\section{Introduction}

Lung cancer, which is strongly associated with tobacco use, is a leading cause of cancer-related mortality worldwide (1). Despite the progress of therapeutic modalities, the prognosis of patients with lung cancer remains poor $(2,3)$.

Over the past decade, epidermal growth factor receptor (EGFR)-specific tyrosine kinase inhibitors (TKIs), which are molecular-targeted drugs, have been reported to be effective for the treatment of non-small cell lung cancer with EGFR mutation $(4,5)$. This mutation is frequently found in never smokers and cases of adenocarcinoma (6), whereas it is uncommon in patients with a smoking history of $>13-25$ pack-years or in those who have not stopped smoking cigarettes $<10-25$ years ago (7-9).

Although smoking is a risk factor for lung cancer, pulmonary emphysema (10) and pulmonary obstructive disorders (11) are also independent risk factors. Patients with interstitial lung disease (ILD), such as combined pulmonary fibrosis and emphysema (CPFE), which is an emerging entity that is strongly associated with tobacco use (12), frequently develop lung cancer $(13,14)$. As shown in a previous study, all lung cancer patients with ILD were reported to be smokers (15). These reports suggest that the presence of emphysema and/or ILD may negatively correlate with the development of EGFR-mutant lung cancer, which is relatively uncommon in smokers (6). However, the prevalence of these underlying diseases in smokers with EGFR-mutant lung cancer remains unclear. 
The present study was conducted to examine the correlation between the EGFR mutation status and the prevalence of underlying lung disease in smokers with lung cancer.

\section{Patients and methods}

Patients. The records for all consecutive patients with non-small cell or non-squamous cell lung cancer who underwent surgical resection at the Ibarakihigashi National Hospital (Ibaraki, Japan) from January, 2007 through December, 2010 were retrospectively investigated. According to previous studies $(8,9)$, it was ensured that only those patients who had a smoking history of $\geq 15$ pack-years were selected from these records. Patient characteristics such as smoking intensity and tumor site were also evaluated. This study was approved by the Institutional Human Ethics Committee of the Ibaraki-higashi National Hospital.

Radiographic analysis. For each patient, a helical computed tomography (CT) scanner was utilized (slice thickness, $2.5-10 \mathrm{~mm}$ ). In the majority of patients, the slice thickness was $\leq 5.0 \mathrm{~mm}$ (window level, - 600 ; window width, 1,500). All measurements were independently performed by a board-certified radiologist and a board-certified pulmonologist, who were both blinded to the clinical data. CT images at three levels were evaluated: the top of the aortic arch, the tracheal carina, and $2 \mathrm{~cm}$ above the highest hemidiaphragm. In each slice, right and left images were assessed separately, and therefore six images in total were evaluated for each patient. The severity of emphysematous changes was scored visually according to the scoring system described by Goddard et al (16). Emphysematous changes were defined as the areas of low attenuation and vascular disruption $(16,17)$. Based on the percentage of emphysematous area in the evaluated lung, each image was classified as normal (score 0 ), $<25 \%$ affected (score 1 ), $<50 \%$ affected (score 2 ), $<75 \%$ affected (score 3 ), or $\geq 75 \%$ affected (score 4 ). Scores obtained by the two reviewers were summed for each image. The maximum possible scores were eight in one image, 16 in one slice, and 48 in the whole lung.

Interstitial changes were defined as the presence of groundgrass opacities, consolidation, reticular shadows, honeycombing and/or traction bronchiectasis or bronchiolectasis, as described in previous studies $(12,15)$. If one or more of these findings were observed, the patients were evaluated as having ILD.

In addition, we focused on the ipsilateral image of the lung nearest to the tumor among the six images (defined as 'ipsilateral image') as shown in Fig. 1, for the purpose of assessing pulmonary status in the area surrounding the tumor.

Pulmonary function analysis. Pulmonary function testing was performed by trained technicians according to the criteria of the American Thoracic Society (18). In all patients, no bronchodilator was used since pulmonary function was examined for the purpose of evaluating tolerability to surgical resection. The diagnosis of chronic obstructive pulmonary disease (COPD) was based on the examination of forced expiratory volume (FEV) in $1 \mathrm{sec}\left(\mathrm{FEV}_{1}\right)$ according to the following formula: $\left(\mathrm{FEV}_{1}\right) /$ forced vital capacity $(\mathrm{FVC}) \leq 70 \%$.

Molecular analysis. All patients provided written informed consent for the comprehensive use of the results of molecular

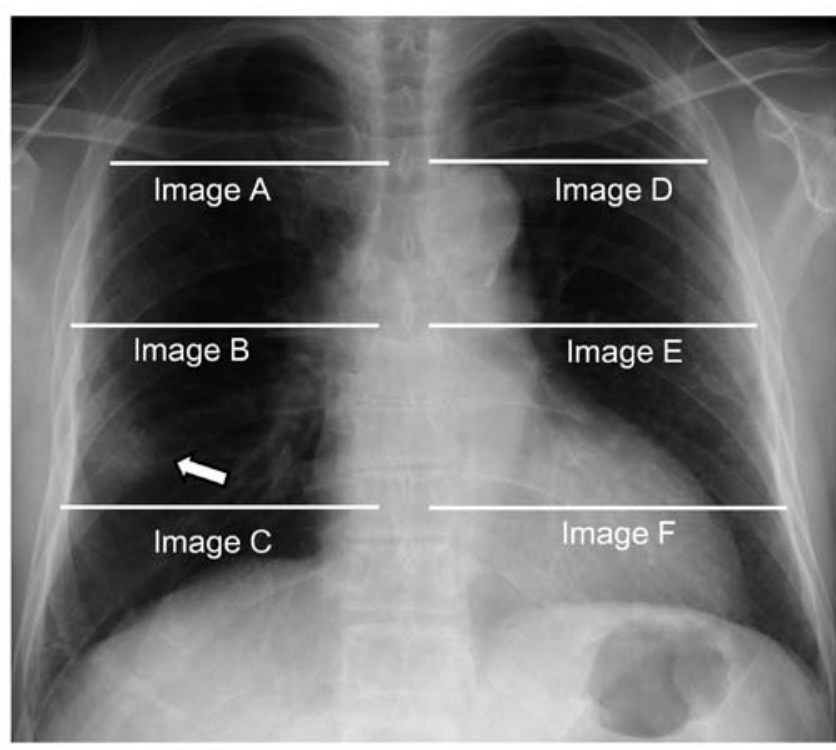

Figure 1. Bars on the chest radiograph show three CT levels: the top of the aortic arch, the tracheal carina and $2 \mathrm{~cm}$ above the highest hemidiaphragm in both lungs. For example, as the tumor presented in the right lower lobe in this case (arrow), the ipsilateral image of the lung nearest to the tumor was 'image C'.

analysis. Genomic DNA samples were isolated from freshfrozen or paraffin-embedded tissues obtained mainly by surgical resection. All clinical samples were independently examined using the peptide nucleic acid-locked nucleic acid polymerase chain reaction clamp method for the detection of EGFR mutations. Testing was performed at the Saitama Medical University (Saitama) or the Mitsubishi Chemical Medience Corporation (Tokyo, Japan) (19).

Statistical analysis. Fisher's exact test were used for the comparison of categorical variables such as gender, pathology, tumor site and pathological stage. The Mann-Whitney U test was performed for continuous variables, including age, pulmonary function variables, and emphysema score. P-values $<0.05$ were considered to indicate statistically significant differences. All analyses were performed using GraphPad Prism 5 software (GraphPad Software, La Jolla, CA, USA).

\section{Results}

Patient characteristics. The study profile is shown in Fig. 2. Of the 292 consecutive patients with non-small cell or nonsquamous cell lung cancer who underwent surgical resection, 97 had a smoking history of $\geq 15$ pack-years. Of these, nine refused to be examined for EGFR mutation status. Of the remaining 88 patients who met the inclusion criteria, 19 (21.6\%) were found positive for the EGFR mutation (exon 21 L858R, $\mathrm{n}=11$; exon 19 deletion, $\mathrm{n}=8$ ).

The 88 patients were divided into two groups according to EGFR mutation status: the mutation-positive group (19 patients) and the wild-type group (69 patients). The characteristics of the patients in these two groups are presented in Table I. Almost all the patients in both groups were males and were diagnosed with adenocarcinoma. The lung tumor 


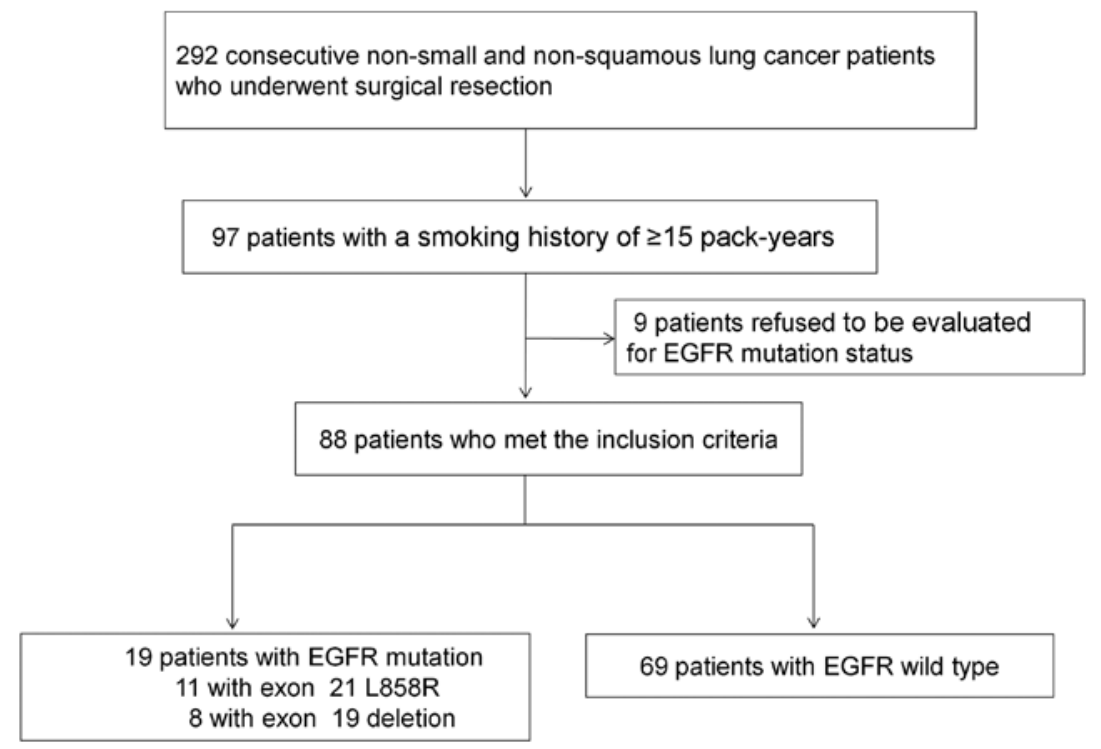

Figure 2. Study profile.

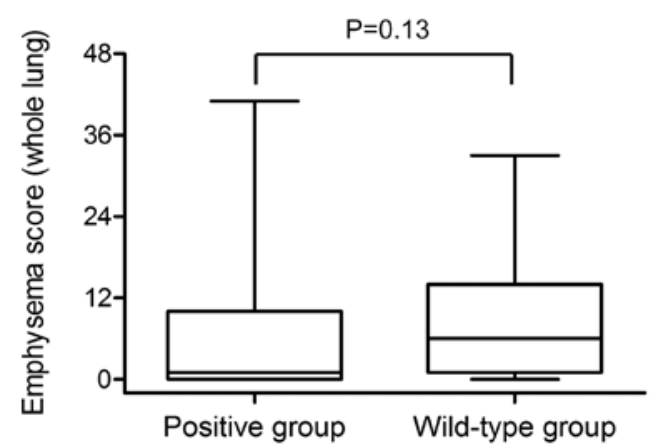

Figure 3. Box plot showing the emphysema score in the whole lung between the two groups. The horizontal bars represent the median values.

sites and smoking status in the mutation-positive group were similar to those in the wild-type group $(\mathrm{P}=0.58$ and 0.80$)$. Patients in the mutation-positive group tended to have lower smoking intensity than those in the wild-type group, although this difference was not significant $(\mathrm{P}=0.07)$. In terms of disease stage and tumor size, the results in the mutation-positive group were similar to those in the wild-type group $(\mathrm{P}=1.00$ and 0.60$)$.

Radiographic analysis. The median emphysema score for the whole lung was one (range, 0-41) in the mutation-positive group and six (range, 0-33) in the wild-type group (Fig. 3). Emphysema scores tended to be lower in the mutation-positive group than in the wild-type group $(\mathrm{P}=0.13)$. Interstitial changes were observed in 19 patients (mutation-positive group, $n=1$; wild-type group, $n=18$ ). Interstitial changes also tended to be less common in the mutation-positive group compared to the wild-type group $(\mathrm{P}=0.06)$.

When we focused on the ipsilateral image, the percentage of patients with emphysematous changes was $26.3 \%$ in the mutation-positive group and $58.0 \%$ in the wild-type group (Table II). Emphysematous changes in the ipsilateral image were less common in the mutation-positive group than in the wild-type group $(\mathrm{P}=0.02)$. Interstitial changes in the ipsilateral image was observed in ten patients. All ten patients were from the wildtype group $(\mathrm{P}=0.11)$. Therefore, the percentage of patients who did not present with emphysematous nor interstitial changes in the ipsilateral image was $73.7 \%$ in the mutation-positive group and $36.2 \%$ in the wild-type group $(\mathrm{P}=0.005)$. The majority of patients in the mutation-positive group had a radiographically normal lung in the ipsilateral image.

Pulmonary function analysis. Median vital capacity (VC)/ predicted VC (\% VC) was $106.7 \%$ (range, 69.8-140.2\%) in the mutation-positive group and $101.8 \%(67-152.9 \%)$ in the wildtype group. The difference between the groups for this parameter was not significant $(\mathrm{P}=0.95)$. In $\mathrm{FEV}_{1} \%$ testing, similar results were observed for both groups (mutation-positive group: 69.9\%, range, 39.1-93.7; wild-type group: 71.5\%, range, 44.6-95.0; $\mathrm{P}=0.94)$. The percentage of patients who met the diagnostic criteria of COPD was $52.6 \%$ in the mutation-positive group and $46.3 \%$ in the wild-type group. The difference between the groups regarding this parameter was not significant $(\mathrm{P}=0.80)$. When the analysis was limited to patients with no interstitial changes, no significant difference was observed between the two groups in terms of \% $\mathrm{VC}$ and $\mathrm{FEV}_{1} \%(\mathrm{P}=0.40$ and 0.43$)$.

\section{Discussion}

In this study, EGFR-mutant lung cancer was commonly observed in the areas where emphysematous and interstitial chnages were absent, even in smokers. This finding suggests that EGFR-mutant lung cancer develops in areas unaffected by smoking, even in smokers.

EGFR mutation is frequently detected in cases of adenocarcinoma as well as in non-smokers $(4,5,20)$. Although the EGFR mutation has been reported to be relatively rare in non-smokers with environmental exposure to tobacco (21), the prevalence of underlying lung disease in non-smokers is low compared to that in smokers. In the present study, we examined smokers with 
Table I. Patient characteristics.

\begin{tabular}{|c|c|c|c|}
\hline \multirow[b]{2}{*}{ Characteristics } & \multicolumn{2}{|c|}{ EGFR mutation status } & \multirow[b]{2}{*}{${ }^{\mathrm{a}} \mathrm{P}$-valu } \\
\hline & $\begin{array}{c}\text { Positive } \\
(\mathrm{n}=19)\end{array}$ & $\begin{array}{l}\text { Wild-type } \\
(\mathrm{n}=69)\end{array}$ & \\
\hline \multicolumn{4}{|l|}{ Gender } \\
\hline Male/female & $19 / 0$ & $63 / 6$ & 0.34 \\
\hline \multicolumn{4}{|l|}{ Age } \\
\hline Years (median) & $\begin{array}{c}72 \\
(46-87)\end{array}$ & $\begin{array}{c}73 \\
(54-81)\end{array}$ & 0.97 \\
\hline \multicolumn{4}{|l|}{ Pathology } \\
\hline Adenocarcinoma & 18 & 62 & \\
\hline $\begin{array}{l}\text { Non-small cell lung cancer } \\
\text { (not otherwise specified } \\
\text { or combined) }\end{array}$ & 1 & 7 & 1.00 \\
\hline $\begin{array}{l}\text { Primary site } \\
\text { (upper lobe/middle } \\
\text { or lingular/lower) }\end{array}$ & $10 / 3 / 6$ & $46 / 6 / 17$ & 0.58 \\
\hline \multicolumn{4}{|l|}{ Smoking history } \\
\hline Current/former & $8 / 11$ & $33 / 36$ & 0.80 \\
\hline \multicolumn{4}{|l|}{ Smoking intensity, duration } \\
\hline Pack-years, median & $\begin{array}{c}38 \\
(15-68)\end{array}$ & $\begin{array}{c}40 \\
(15-144)\end{array}$ & 0.07 \\
\hline \multicolumn{4}{|l|}{ Pathological stage } \\
\hline $\begin{array}{l}\text { I and II } \\
\text { III and IV }\end{array}$ & $\begin{array}{r}15 \\
4\end{array}$ & $\begin{array}{l}52 \\
17\end{array}$ & 1.00 \\
\hline Tumor size (median, $\mathrm{mm}$ ) & $\begin{array}{c}25 \\
(15-65)\end{array}$ & $\begin{array}{c}27 \\
(10-100)\end{array}$ & 0.60 \\
\hline
\end{tabular}

${ }^{a}$ Comparison between the EGFR mutation positive group and the wild-type group. EGFR, epidermal growth factor receptor.

a smoking history of $\geq 15$ pack-years; this history was found to negatively correlate with the presence of EGFR mutation, and as shown by our results, EGFR-mutant lung cancer was commonly observed in areas where emphysematous and interstitial changes were absent. To the best of our knowledge, only one previous study on the correlation of the EGFR mutation status with underlying lung diseases, such as emphysema and pulmonary fibrosis has been published [Usui et al (22)]. In their study, the frequency of EGFR mutation was reported low in patients with emphysema and pulmonary fibrosis compared to those without. Although the results of that study seem consistent with those in the current study, their results included both never smokers and smokers (never smokers, 37.4\%; smokers, $62.6 \%$ ). Furthermore, lung cancer was at an advanced clinical stage in the majority of patients (stage IIIB and IV, 68.2\%) and only the presence of emphysema and/or fibrosis in the whole lung was roughly evaluated in that study (22). In the present study, the detailed radiographic evaluation focused on the six images from the whole lung, and the results revealed that emphysematous changes in the image nearest to the tumor
Table II. EGFR mutation status and underlying lung disease in the ipsilateral image of the lung nearest to the tumor.

\begin{tabular}{|c|c|c|c|}
\hline \multirow[b]{2}{*}{ Underlying lung disease } & \multicolumn{2}{|c|}{ EGFR mutation status } & \multirow[b]{2}{*}{ P-value } \\
\hline & $\begin{array}{c}\text { Positive } \\
19 \text { cases }(\%)\end{array}$ & $\begin{array}{l}\text { Wild-type } \\
69 \text { cases }(\%)\end{array}$ & \\
\hline \multicolumn{4}{|l|}{ Emphysematous changes } \\
\hline Present & $5(26.3)$ & $40(58.0)$ & $0.02^{\mathrm{a}}$ \\
\hline Absent & $14(73.7)$ & $29(42.0)$ & \\
\hline \multicolumn{4}{|l|}{ Emphysema score } \\
\hline 0 & $14(73.7)$ & $29(42.0)$ & \\
\hline$>0$ to $\leq 2$ & $1(5.3)$ & $22(31.9)$ & \\
\hline$>2$ to $\leq 4$ & $3(15.8)$ & $13(18.8)$ & \\
\hline$>4$ to $\leq 6$ & $0 \quad(0.0)$ & $3(4.3)$ & \\
\hline$>6$ to $\leq 8$ & $1(5.3)$ & $2(2.9)$ & \\
\hline \multicolumn{4}{|l|}{ Interstitial changes } \\
\hline Present & $0(0.0)$ & $10(14.5)$ & 0.11 \\
\hline Absent & $19(100.0)$ & $59(85.5)$ & \\
\hline \multicolumn{4}{|l|}{$\begin{array}{l}\text { Emphysematous and/or } \\
\text { interstitial changes }\end{array}$} \\
\hline Present & $5(26.3)$ & $44(63.8)$ & $0.005^{\mathrm{a}}$ \\
\hline Absent & $14(73.7)$ & $25(36.2)$ & \\
\hline
\end{tabular}

andicates statistical significance. EGFR, epidermal growth factor receptor.

Table III. Prevalence of EGFR mutation in patients with underlying lung disease detected in the ipsilateral image of the lung nearest to the tumor.

\begin{tabular}{lccc}
\hline $\begin{array}{l}\text { Underlying lung } \\
\text { disease }\end{array}$ & $\begin{array}{c}\text { No. of patients with } \\
\text { EGFR mutation }\end{array}$ & $\begin{array}{c}\text { Total no. } \\
\text { of patients }\end{array}$ \\
\hline Emphysematous changes & 5 & 45 & 11.1 \\
Interstitial changes & 0 & 10 & 0 \\
None & 14 & 39 & 35.9
\end{tabular}

EGFR, epidermal growth factor receptor.

were less common in the mutation-positive group. Therefore, EGFR-mutant lung cancer may develop in areas that appear radiographically normal, even in smokers.

The precise mechanism accounting for the results of this study remains unknown. However, it is generally accepted that the presence of emphysema is related to the development of lung cancer $(10,23-25)$. In addition, patients with ILD such as CPFE, which is strongly associated with tobacco use, have been reported to develop lung cancer more frequently than those with emphysema alone (12-14). Recent reports indicate that patients with underlying lung diseases are susceptible to smoking-related inflammation, which may ultimately contribute to lung cancer development $(13,22,23,26,27)$. Although the mechanisms underlying this association have not been clearly 
identified, the results of the present study may indicate a clinical possibility: EGFR-mutant lung cancer may develop in areas less affected by tobacco use and the mechanism of carcinogenesis in EGFR-mutant lung cancer in smokers may resemble that in non-smokers. In the present study, EGFR-mutant lung cancer in smokers was commonly observed in the areas where emphysematous and interstitial changes were absent compared to wild-type lung cancer. Of note, although the degree of emphysematous changes in the whole lung was not significantly different between the two groups $(\mathrm{P}=0.13)$, the difference became clearer when the assessment of emphysematous changes focused on the ipsilateral image $(\mathrm{P}=0.02)$. These results suggest that the absence of emphysematous and interstitial changes in the ipsilateral image, not in the whole lung, is correlated with the development of EGFR-mutant lung cancer.

The results of this study may provide two important implications for clinical practice. First, EGFR-TKIs may be effective for EGFR-mutant lung cancer even in smokers. Previous studies have reported no differences in progression-free and overall survival rates between smokers and non-smokers with EGFRmutant lung cancer $(22,28-30)$. However, detailed information regarding smoking intensity was not provided in those reports. Lung cancer in smokers has been associated with more widespread chromosomal abnormalities than in non-smokers (31). Therefore, various genetic alterations in patients with lung cancer may be associated with resistance to EGFR-TKIs. For example, EGFR-mutant lung cancer other than adenocarcinoma has been reported to exhibit a poor response to EGFR-TKIs, indicating that multiple factors other than EGFR signaling may play an important role in carcinogenesis and tumor growth $(32,33)$. Considering that EGFR-mutant lung cancer was commonly observed in the areas where emphysematous and interstitial changes were absent even in smokers, these tumors may bear a genetic resemblance to those in nonsmokers. Therefore, these tumors, similar to the ones found in non-smokers, may respond well to EGFR-TKI treatment, although, the fatal adverse effects of ILD should be carefully monitored in smokers (34). Second, smokers without emphysematous and interstitial changes may have a high possibility of developing EGFR-mutant lung cancer compared to those with such changes. The present study revealed that EGFR mutation was found in 5/45 $(11.1 \%)$ patients with emphysematous changes, $0 / 10(0 \%)$ patients with interstitial changes and $14 / 39(35.9 \%)$ patients without these underlying diseases in the ipsilateral image (Table III). Although a number of studies have revealed that the prevalence of EGFR mutation in smokers ranges from 8.4 to $15.6 \%(8,28,30)$, the prevalence of EGFR mutation in smokers without emphysematous and interstitial changes seems much higher. Therefore, our results indicate the importance of evaluating the EGFR mutation status in patients with no emphysematous nor interstitial changes in the ipsilateral lung near the tumor, regardless of smoking history.

The present study had several limitations. First, the study was carried out at a single institution and was a retrospective study with a small sample size. In addition, the slice thickness of the CT images in the majority of patients was $\leq 5.0 \mathrm{~mm}$; therefore, the results do not reflect the evaluation of the highresolution $\mathrm{CT}$ images and thus, the prevalence of underlying lung disease could be underestimated. Finally, the evaluation of emphysema was conducted visually and semiquantitatively, not automatically or densitometrically. However, a systemic review and meta-analysis by Smith et al (25) reported a significant association of lung cancer risk with emphysema detected by visual evaluation rather than by automated methods.

In conclusion, our results revealed that EGFR-mutant lung cancer was commonly observed in the areas where emphysematous and interstitial changes were absent, even in smokers. EGFR-mutant lung cancer definitely exists in smokers and may develop in areas that appear radiographically normal. It would be important to evaluate the EGFR mutation status in patients with no emphysematous or interstitial changes in the ipsilateral lung near the tumor, regardless of smoking history. The results of this study should be confirmed in a future prospective study.

\section{Acknowledgements}

We thank Ms. Kimiko Sakurai for providing secretarial assistance.

\section{References}

1. Wynder EL and Graham EA: Landmark article May 27, 1950: Tobacco Smoking as a possible etiologic factor in bronchiogenic carcinoma. A study of six hundred and eighty-four proved cases. By Ernest L. Wynder and Evarts A. Graham. JAMA 253: 2986-2994, 1985.

2. Schiller JH, Harrington D, Belani CP, et al: Comparison of four chemotherapy regimens for advanced non-small-cell lung cancer. N Engl J Med 346: 92-98, 2002.

3. Ohe Y, Ohashi Y, Kubota K, et al: Randomized phase III study of cisplatin plus irinotecan versus carboplatin plus paclitaxel, cisplatin plus gemcitabine, and cisplatin plus vinorelbine for advanced non-small-cell lung cancer: Four-Arm Cooperative Study in Japan. Ann Oncol 18: 317-323, 2007.

4. Paez JG, Janne PA, Lee JC, et al: EGFR mutations in lung cancer: correlation with clinical response to gefitinib therapy. Science 304: 1497-1500, 2004.

5. Lynch TJ, Bell DW, Sordella R, et al: Activating mutations in the epidermal growth factor receptor underlying responsiveness of non-small-cell lung cancer to gefitinib. N Engl J Med 350: 2129-2139, 2004

6. Kosaka T, Yatabe Y, Endoh H, Kuwano H, Takahashi T and Mitsudomi T: Mutations of the epidermal growth factor receptor gene in lung cancer: biological and clinical implications. Cancer Res 64: 8919-8923, 2004.

7. Lee YJ, Shim HS, Kang YA, et al: Dose effect of cigarette smoking on frequency and spectrum of epidermal growth factor receptor gene mutations in Korean patients with non-small cell lung cancer. J Cancer Res Clin Oncol 136: 1937-1944, 2010.

8. Pham D, Kris MG, Riely GJ, et al: Use of cigarette-smoking history to estimate the likelihood of mutations in epidermal growth factor receptor gene exons 19 and 21 in lung adenocarcinomas. J Clin Oncol 24: 1700-1704, 2006.

9. Jida M, Toyooka S, Mitsudomi T, et al: Usefulness of cumulative smoking dose for identifying the EGFR mutation and patients with non-small-cell lung cancer for gefitinib treatment. Cancer Sci 100: 1931-1934, 2009.

10. Wilson DO, Weissfeld JL, Balkan A, et al: Association of radiographic emphysema and airflow obstruction with lung cancer. Am J Respir Crit Care Med 178: 738-744, 2008.

11. Maldonado F, Bartholmai BJ, Swensen SJ, Midthun DE, Decker PA and Jett JR: Are airflow obstruction and radiographic evidence of emphysema risk factors for lung cancer? A nested case-control study using quantitative emphysema analysis. Chest 138: 1295-1302, 2010.

12. Cottin V, Nunes H, Brillet PY, et al: Combined pulmonary fibrosis and emphysema: a distinct underrecognised entity. Eur Respir J 26: 586-593, 2005.

13. Usui K, Tanai C, Tanaka Y, Noda $\mathrm{H}$ and Ishihara T: The prevalence of pulmonary fibrosis combined with emphysema in patients with lung cancer. Respirology 16: 326-331, 2011. 
14. Kitaguchi Y, Fujimoto K, Hanaoka M, Kawakami S, Honda T and Kubo K: Clinical characteristics of combined pulmonary fibrosis and emphysema. Respirology 15: 265-271, 2010.

15. Kenmotsu H, Naito T, Kimura M, et al: The risk of cytotoxic chemotherapy-related exacerbation of interstitial lung disease with lung cancer. J Thorac Oncol 6: 1242-1246, 2011

16. Goddard PR, Nicholson EM, Laszlo G and Watt I: Computed tomography in pulmonary emphysema. Clin Radiol 33: 379-387, 1982.

17. Bergin C, Muller N, Nichols DM, et al: The diagnosis of emphysema. A computed tomographic-pathologic correlation. Am Rev Respir Dis 133: 541-546, 1986.

18. Ferguson GT, Enright PL, Buist AS and Higgins MW: Office spirometry for lung health assessment in adults: A consensus statement from the National Lung Health Education Program. Chest 117: 1146-1161, 2000.

19. Nagai Y, Miyazawa H, Huqun, et al: Genetic heterogeneity of the epidermal growth factor receptor in non-small cell lung cancer cell lines revealed by a rapid and sensitive detection system, the peptide nucleic acid-locked nucleic acid PCR clamp. Cancer Res 65: 7276-7282, 2005.

20. Takano T, Ohe Y, Sakamoto H, et al: Epidermal growth factor receptor gene mutations and increased copy numbers predict gefitinib sensitivity in patients with recurrent non-small-cell lung cancer. J Clin Oncol 23: 6829-6837, 2005.

21. Lee YJ, Cho BC, Jee SH, et al: Impact of environmental tobacco smoke on the incidence of mutations in epidermal growth factor receptor gene in never-smoker patients with non-small-cell lung cancer. J Clin Oncol 28: 487-492, 2010.

22. Usui K, Ushijima T, Tanaka Y, et al: The frequency of epidermal growth factor receptor mutation of nonsmall cell lung cancer according to the underlying pulmonary diseases. Pulm Med 2011: 290132, 2011.

23. Gullon JA, Suarez I, Medina A, Rubinos G, Fernandez R and Gonzalez I: Role of emphysema and airway obstruction in prognosis of lung cancer. Lung Cancer 71: 182-185, 2011.

24. de Torres JP, Bastarrika G, Wisnivesky JP, et al: Assessing the relationship between lung cancer risk and emphysema detected on low-dose CT of the chest. Chest 132: 1932-1938, 2007.
25. Smith BM, Pinto L, Ezer N, Sverzellati N, Muro S and Schwartzman K: Emphysema detected on computed tomography and risk of lung cancer: a systematic review and meta-analysis. Lung Cancer 77: 58-63, 2012.

26. Yamada N, Yamaya M, Okinaga S, et al: Microsatellite polymorphism in the heme oxygenase-1 gene promoter is associated with susceptibility to emphysema. Am J Hum Genet 66: 187-195, 2000.

27. Kikuchi A, Yamaya M, Suzuki S, et al: Association of susceptibility to the development of lung adenocarcinoma with the heme oxygenase-1 gene promoter polymorphism. Hum Genet 116: 354-360, 2005.

28. D'Angelo SP, Pietanza MC, Johnson ML, et al: Incidence of EGFR exon 19 deletions and L858R in tumor specimens from men and cigarette smokers with lung adenocarcinomas. J Clin Oncol 29: 2066-2070, 2011.

29. Morita S, Okamoto I, Kobayashi K, et al: Combined survival analysis of prospective clinical trials of gefitinib for non-small cell lung cancer with EGFR mutations. Clin Cancer Res 15: 4493-4498, 2009.

30. Rosell R, Moran T, Queralt C, et al: Screening for epidermal growth factor receptor mutations in lung cancer. $\mathrm{N}$ Engl J Med 361: 958-967, 2009.

31. Sanchez-Cespedes M, Ahrendt SA, Piantadosi S, et al: Chromosomal alterations in lung adenocarcinoma from smokers and nonsmokers. Cancer Res 61: 1309-1313, 2001.

32. Shukuya T, Takahashi T, Kaira R, et al: Efficacy of gefitinib for non-adenocarcinoma non-small-cell lung cancer patients harboring epidermal growth factor receptor mutations: a pooled analysis of published reports. Cancer Sci 102: 1032-1037, 2011.

33. Castillo L, Etienne-Grimaldi MC, Fischel JL, Formento P, Magne N and Milano G: Pharmacological background of EGFR targeting. Ann Oncol 15: 1007-1012, 2004.

34. Kudoh S, Kato H, Nishiwaki Y, et al: Interstitial lung disease in Japanese patients with lung cancer: a cohort and nested casecontrol study. Am J Respir Crit Care Med 177: 1348-1357, 2008. 